\title{
Evolutionary Modeling to Evaluate the Shear Behavior of Circular Reinforced Concrete Columns
}

\author{
Alessandra Fiore, Giuseppe Carlo Marano, Daniele Laucelli, and Pietro Monaco \\ Department of Science of Civil Engineering and Architecture, Technical University of Bari (Politecnico di Bari), Via Orabona 4, \\ 70125 Bari, Italy \\ Correspondence should be addressed to Alessandra Fiore; a.fiore@poliba.it
}

Received 27 February 2014; Revised 4 August 2014; Accepted 18 August 2014; Published 7 September 2014

Academic Editor: Hossein Moayedi

Copyright (C) 2014 Alessandra Fiore et al. This is an open access article distributed under the Creative Commons Attribution License, which permits unrestricted use, distribution, and reproduction in any medium, provided the original work is properly cited.

\begin{abstract}
Despite their frequent occurrence in practice, only limited studies on the shear behavior of reinforced concrete (RC) circular members are available in the literature. Such studies are based on poor assumptions about the physical model, often resulting in being too conservative, as well as technical codes that essentially propose empirical conversion rules. On this topic in this paper, an evolutionary approach named EPR is used to create a structured polynomial model for predicting the shear strength of circular sections. The adopted technique is an evolutionary data mining methodology that generates a transparent and structured representation of the behavior of a system directly from experimental data. In this study experimental data of $61 \mathrm{RC}$ circular columns, as reported in the technical literature, are used to develop the EPR models. As final result, physically consistent shear strength models for circular columns are obtained, to be used in different design situations. The proposed formulations are compared with models available from building codes and literature expressions, showing that EPR technique is capable of capturing and predicting the shear behavior of RC circular elements with very high accuracy. A parametric study is also carried out to evaluate the physical consistency of the proposed models.
\end{abstract}

\section{Introduction}

It is well known that columns are the most vulnerable elements in reinforced concrete (RC) structures. These elements are principally designed to bear axial loads, but as a result of lateral loads, for example, wind pressure or earthquake ground motion, they could deal with relevant shear loads and thus should inevitably be designed to avoid possible shear failures [1-6]. Composite and steel columns [7] are particularly suitable at this aim.

Circular columns are very popular for bridge pier design, due to simplicity of construction and because their strength characteristics under wind and seismic loads are similar in any direction. Circular elements are also used extensively as columns in buildings, or as piles for foundations, or as secant piling to form diaphragm walls. Despite their frequent occurrence in practice, only limited researches on the shear behavior of RC circular members have been carried out.

Most of the researchers and codes state that the shear strength $V_{\mathrm{Rd}}$ of a beam is the sum of the contributions of concrete $V_{c}$ and shear reinforcement $V_{s}$, if present. The first takes into account the shear stress transferred by the compressed zone of the beam, the dowel action, the aggregate interlock, and the arch effect and depends on many factors, such as the tensile longitudinal steel ratio, concrete grade, aggregate size, or shear span, among others. The evaluation of this term is debatable and originates on empirical methods. Traditional codes, therefore, propose empirical formulas derived from various tests developed in rectangular sections and then extrapolating results for arbitrary sections, such as circular ones. Also the evaluation of the contribution of the hoops obtained from the truss analogy for rectangular sections was later extended to arbitrary sections, but no specific address was developed for circular ones.

A very limited number of shear models for circular section members exist in the literature. Ghee et al. [8] proposed a model for columns subjected to cyclic loading, consisting of a purely empirical concrete and a classical shear reinforcement contribution, where shear crack inclination 
was obtained by using a lower bound plasticity model. The concrete contribution for low flexural ductility was defined as the "initial concrete strength" and calculated as strength at maximum lateral load; the transverse reinforcement capacity was calculated from 45-degree truss mechanisms assuming that transverse reinforcement exposed by a presumed 45degree diagonal crack is at yield. At higher flexural ductility, a degradation of the concrete term was assumed and the "final concrete strength" was proposed. Different adjustments to this basic model have been added over the years by various authors. Priestley et al. [9] modified the model proposed by Ghee et al. [8] and separated the shear capacity term of the axial load arch mechanism $V_{p}$, from the concrete term $V_{c}$. Other modifications to Ghee et al. original model [8] were developed by Wong et al. [10] and by Kowalsky and Priestley [11]. In this work, the authors revised the model proposed by Priestley et al. [9] and the effect of the aspect ratio and longitudinal reinforcement ratio was incorporated.

In addition, the truss mechanism component developed by Ghee et al. [8] has been slightly modified assuming that, in the member compression zone, the cracks are by definition closed.

A different approach was due to Collins et al. [12] by means of the application of the Modified Compression Field Theory (MCFT) [13] to deal with shear strength prediction of circular members. Moreover, this type of approach is more complex than those usually based on strut and tie models, which are still used in many applications, till their first implementation in early 1900, thanks to their simplicity. The practical application of the MCFT requires its implementation as a calculation algorithm within a computer routine, thus strongly increasing the complexity level, also for a standard code formulation.

Bentz et al. [14] described a simpler version of the MCFT, from which the shear design rules described in AASHTO LRFD [15] were derived and which also contains rules for shear design of circular members. Turmo et al. [16] proposed an analytical model for evaluating the contribution of the transverse reinforcement in concrete members of solid and hollow circular cross section, consisting in an accurate formula for evaluating the shear transferred by spiral reinforcement in solid members. The calculation of hollow core circular columns with both vertical and spiral reinforcement was also deduced.

Recently Merta [17] proposed a model based on the truss analogy by adding a concrete contribution term to the capacity of the shear reinforcement. An additional deviatoric shear resisting mechanism of hoops, present exclusively in members with curved transverse reinforcement, was identified and expressed analytically. It is explained by the fact that a curved reinforcing bar under tension induces compression in radial direction as well. The component of this compressive force in the direction of external shear could thus be considered as an additional shear enhancing mechanism of the hoops. Its magnitude is expressed through the friction force that is present between the concrete and steel after the section is cracked and the bond is partially destroyed. Under these assumptions, the concrete shear capacity was derived by a parametric study.
1.1. Experimental Approaches to Shear Capacity of Circular Members Modeling. As for theoretical researches, also experimental studies on the shear capacity of circular members are quite limited. Assuming that the extrapolation of tests on rectangular beams may not be accurate for evaluating circular members shear strength, some researchers performed different test campaigns in such structural elements. Moreover, all the above-mentioned models are derived starting from a mechanical simplified model, whose parameters come from the extrapolation of experimental tests for evaluating circular member shear strength. In their paper, Clarke and Birjandi [18] reported also test results from different previous experimental studies, in particular:

(i) Capon and Cossio [19] who tested 21 members, mainly of $250 \mathrm{~mm}$ in diameter, having only longitudinal steel, but four that had stirrups; eleven of the specimens are reported as failing in shear, two with stirrups and nine without;

(ii) Khalifa and Collins [20] who tested five columns, all of $445 \mathrm{~mm}$ in diameter; these were subject to an axial load of $1000 \mathrm{kN}$, equivalent to a stress of $6.4 \mathrm{MPa}$, and all specimens failed in shear;

(iii) Nagato [21] whose tests involved 16 columns, all with a diameter of $300 \mathrm{~mm}$, with and without transverse reinforcement, and with and without axial stress; all specimens are reported as failing in shear.

Later on, Ghee et al. [8] tested 25 circular columns under axial load and cyclic lateral inelastic displacements, 24 of them failing in shear. The columns had a diameter of $400 \mathrm{~mm}$. Variables in the test included axial load level, longitudinal reinforcement ratio, transverse reinforcement ratio, and aspect ratio. They addressed, for the first time, the efficiency of circular hoops and deduced the formula for calculating $V_{s}$ presuming a 45-degree diagonal tension crack and vertical reinforcement. The work of Ghee et al. [8] was completed by Priestley et al. $[9,22]$ which takes into account the potential development of steeper angles of cracking other than 45-degree one. Various experimental researches on circular RC members loaded monotonically in shear were aimed at verifying the possibility to extend to circular sections the use of design equations developed for rectangular sections [18-20].

Lee et al. [23] tested 4 full scale circular column specimens, which show shear related behavior under cyclic lateral load with constant axial force. The test variables are aspect ratio, transverse steel configuration (with or without crossties), and longitudinal steel ratio. The columns showed flexural failure or flexure-shear failure depending on the test variables. The test results were compared with shear strength equations adopted by the bridge seismic design specifications or guidelines and proposed by other researchers. The study showed that the accuracy of each method for shear strength prediction also depends on the aspect ratio and the relative steel amount of longitudinal reinforcement and transverse reinforcement.

More recently, Jensen and Hoang [24] presented the results of a test series on heavily shear reinforced circular 
concrete members. The specimens had shear reinforcement percentages up to more than three times the maximum percentage found in existing tests. The test results indicate that it is possible to obtain shear strengths which exceed the upper limit usually imposed on rectangular members. The test results are compared with a recently developed plasticity-based shear model for circular members. Satisfactory agreement was found. Comparisons were also made with calculations using the AASHTO LRFD [15] design code. It was found that the AASHTO LRFD design code gives reasonable results for members with small amounts of shear reinforcement while it underestimates the shear strength for heavily shear reinforced members.

This paper proposes an innovative approach, mainly based on experimental data, in order to develop an explicit compact expression to assess the shear strength of RC circular columns. Such approach is based on the evolutionary polynomial regression (EPR) [25], which is a hybrid data-driven technique that combines the effectiveness of evolutionary search with the advantage of classical numerical regression for developing data-driven models (i.e., input-output relationships) featured by explicit mathematical expression. The EPR technique has been successfully applied to modeling a wide range of complex engineering problems including constitutive modeling of soils; stability of slopes; settlement of foundations; liquefaction of soils due to earthquake and a number of other applications in civil engineering [26-28].

The EPR implements a multiobjective genetic algorithms (MOGA) optimization paradigm in order to search for model expressions as trade-off between fitness to data and complexity of mathematical formulations [29]. The main advantage of the MOGA EPR approach is the possibility to select models from a set of optimal solutions according to the specific application and to the physical insight of the analyst.

\section{Proposed Models for Shear Strength and Contemporary Code Provisions of Circular Reinforced Concrete Columns}

Shear strength of reinforced concrete has received considerable attention in research during the past century. Several models for column shear strength have been proposed and used for design of new buildings and assessment of existing buildings.

Shear reinforcements are used to ensure that the element fails in flexure; the addition shear reinforcement affects the mechanism by which shear is carried by a beam in several ways: shear reinforcement carries tensile actions across cracks, confines the compression-zone concrete increasing its shear capacity, encloses the flexural reinforcement, and can prevent dowel-splitting of the concrete. Moreover, for a given applied load, equilibrium of a cracked section with stirrup requires a shorter crack length but a larger crack width, that one without stirrup and the shape of the crack will also differ. Shear transfer mechanism in beam with stirrups has not been examined in so much detail as that in beams without stirrups.

Truss analogies are most commonly used in the design. The assumed internal equilibrium state comprises tensile shear reinforcement and inclined compressive struts of concrete. The original Mörsch truss analogy [30] uses a $45^{\circ}$ strut angle and predicts failure when the shear reinforcements are at yield. The modified truss analogy [31] established an optimal lower bound for the shear capacity by varying the compressive strut angle to give reinforcement yield and web concrete failure simultaneously.

Even if shear transfer mechanisms are qualitatively well known, there is no agreement on the quantification of the shear strength of concrete members. As the value of $V_{s}$ can be easily calculated with rational models, such as the truss analogy, research focuses on the elaboration of methods for an accurate evaluation of $V_{c}$. The concrete shear capacity is the capacity of the section without shear reinforcement: due to the complex stress redistribution after cracking, the shear transfer mechanisms of RC element have not been clearly understood yet. Its evaluation is very controversial and always relies, somehow, on empirical methods considering its dependence from various factors, such as the tensile longitudinal steel ratio, concrete grade, aggregate size, or shear span, among others. Present shear researches concern use of self-training algorithms to predict $V_{c}$ or the development and application of equilibrium methods and equilibriumcompatibility methods, such as the Modified Compression Field Theory [13]. The same interest has not been dedicated to improve the evaluation of the shear reinforcement contribution.

In this framework the shear strength of circular concrete columns has not received as much attention as rectangular ones and it is interesting to note that there are not guidelines for shear capacity in some international codes; likewise, many others prescribe that the shear capacity of a circular section equals the capacity of an equivalent rectangular section [32]. In effect, this kind of approach has not been fully validated by test evidence and it obviously is questionable because in circular sections hoops contribute differently to the shear strength compared with rectangular stirrups.

In this section, a review of the shear strength provisions of various contemporary design code and proposed models is developed for circular columns. Most design codes include contributions from concrete $V_{c}$ and transverse reinforcement $V_{s}$ to analyze the shear strength of circular columns. The two components are then summed to estimate the total shear strength in

$$
V=V_{c}+V_{s}
$$

One should point out that, generally, codified methods of design cannot be considered as predictive equations, since they are intended to provide only a conservative and safe lower bound to strength. Therefore, most shear design codes use empirical or semiempirical models for predicting shear strengths. The American code [15] and the New Zealand one [33] explicitly refer to circular concrete members, but with simplified methods. These recommend the calculation of the shear carried by the truss mechanism by representing the section as an equivalent rectangle having a width equal to the diameter $D$ and an effective depth equal to $0.8 D$.

Based on a large number of tests on circular cantilever columns under uniaxial load and multidirectional cyclic 
displacements, Ghee et al. [8] proposed a model for the shear strength of circular sections under cyclic load by adopting an additive approach based on the contribution from concrete and transverse reinforcement. The concrete contribution for low flexural ductility $(\mu<2)$ was defined as the "initial concrete strength" and calculated as a strength at maximum lateral load as follows:

$$
V_{c}=0.37 \alpha\left(1+\frac{3 P}{f_{c}^{\prime} A_{g}}\right) \sqrt{f_{c}^{\prime}} A_{e} \quad(\text { in } \mathrm{N}),
$$

where $P$ is the axial load, $A_{g}$ is the cross-sectional area, and $f_{c}^{\prime}$ is the concrete compressive strength. The effective area $A_{e}$ is proposed as 0.8 times the cross-sectional area $A_{g}$, which approximately corresponds to the area of the confined concrete core.

For low aspect ratios $(a / D<2)$, the shear capacity enhancement factor $\alpha$ was proposed as

$$
\alpha=\frac{2}{a / D} \geq 1.0
$$

where $a$ is the shear span and $D$ is the section's diameter. The transverse reinforcement capacity was calculated from 45-degree truss mechanisms as follows:

$$
V_{s}=\frac{\pi}{2} \frac{A_{\mathrm{sh}} f_{\mathrm{yh}} D^{\prime}}{s}
$$

where $A_{\text {sh }}$ is the area of the shear reinforcement, $s$ is the hoop's spacing, $f_{\mathrm{yh}}$ is their yield strength, and $D^{\prime}$ is the core diameter measured at the center line of the transverse hoop or spiral. It was assumed that all transverse reinforcements exposed by a presumed $45^{\circ}$ diagonal crack are at yield. An integral averaging was imposed assuming that the spacing of the shear reinforcement is sufficiently small compared to the diameter. It was noted that for low $D^{\prime} / s$ ratios the equation can be up to $10 \%$ nonconservative. At higher flexural ductilities $(\mu>2)$, the degradation of the concrete produces a reduced concrete contribution and then a "final concrete strength" is proposed. One should point out that this formulation, such as other ones, implicitly assumes that all hoops exposed by a crack are at yield and also consider a "smeared" distribution of transverse reinforcement, whereas in reality transverse reinforcement consists of a discrete number of hoops that traverse a diagonal crack plane as shown in Figure 1. The later assumption is valid just if the pitch is sufficiently small compared to the diameter $D^{\prime}$.

Clarke and Birjandi [18] proposed to use for circular sections the same shear design approach as given by the British codes of practice BS 5400 [34] for rectangular sections.

However, a modification was suggested; that is, that the section's effective depth should be considered as the distance from the extreme compression fiber to the centroid of the tension reinforcement.

Following this, the effective shear area represents the area corresponding to the effective depth.

The design approach for rectangular section in British codes of practice [34] consists in adding together the concrete

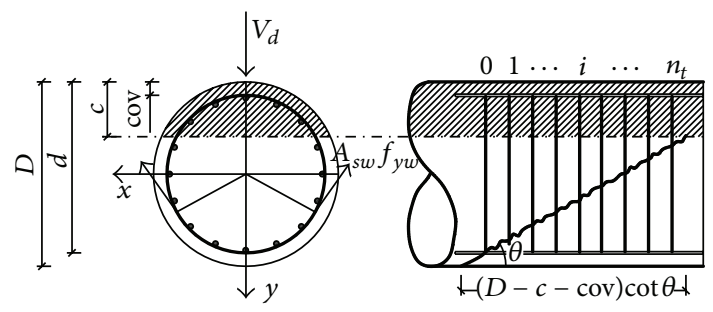

FIgURE 1: Geometrical and mechanical characteristics affecting the shear strength of a circular column.

and transverse reinforcement contributions to the shear capacity. The concrete term is defined as

$$
V_{c}=\left[0.27 \alpha\left(\frac{100 A_{\mathrm{sl}}}{b_{w} d}\right)^{1 / 3}\left(\frac{500}{d}\right)^{1 / 4}\left(f_{\mathrm{cu}}\right)^{1 / 3}\right] b_{w} d,
$$

where $A_{\mathrm{sl}}$ is the area of longitudinal steel, $b_{w}$ is the section's width, $d$ is the effective depth, and $f_{\text {cu }}$ is the concrete cube strength. For loads applied at a distance $a_{v}$ closer than $2 d$ from the support, the concrete shear capacity is increased by

$$
\alpha=\frac{2 d}{a_{v}} \geq 1.0 .
$$

The shear force carried by transverse reinforcement is calculated as

$$
V_{s}=\frac{A_{\mathrm{sh}} f_{\mathrm{yh}} d}{s},
$$

where $A_{\text {sh }}$ is the cross-sectional area of the link's both legs at the section's neutral axis. In a member with axial compression load $P$, the shear capacity should be multiplied by $(1+$ $\left.0.05 P / A_{g}\right)$.

Dancygier [35] modified Ghee's model by adopting a discrete computation of tension-force components developed by reinforcing hoops in the direction of the shear force, given by the following expression:

$$
V_{s}=2 A_{\mathrm{sh}} f_{\mathrm{yh}}\left(\sum_{i=1}^{n} \cos \alpha_{i}\right),
$$

where $i$ is the index of the hoop that is crossed by the inclined crack, $\alpha$ is the angle between its force $\left(A_{\mathrm{sh}} f_{\mathrm{yh}}\right)$ and the direction of the shear force, given by

$$
\sin \alpha_{i}=1-\frac{2 a_{i}}{D^{\prime}}, \quad a_{i}=\left[s_{0}+(i-1) s\right] \cot \theta,
$$

and $n$ is the number of the hoops that are crossed by the crack:

$$
n=\operatorname{roundup}\left(\frac{D^{\prime}}{s} \tan \theta-\frac{s_{0}}{s}\right),
$$

where $s$ is the pitch, $\theta$ is crack's inclination angle, and $s_{0}$ is the distance from the end of the crack to the first hoop that is crossed by it. 
Kowalsky and Priestley [11] discussed Ghee's model considering that in the derivation of the truss mechanism equation it was assumed that a diagonal crack is able to mobilize transverse reinforcement along a crack length extending the full width of the confined core of the concrete. In the compression zone of the column, however, all cracks are by definition closed. Therefore, if the crack is closed, shear cannot be transferred across it by tension strain in the transverse reinforcement. Therefore, it is evident that a reduced column width $-D-c-\operatorname{cov}-$ (Figure 1) is appropriate for calculating the number of hoops mobilized by the cracks between the compression struts and then a revised truss component equation should be adopted. The authors obtained an approximated equation given by

$$
V_{s}=\frac{\pi}{2} A_{s w} f_{y w} \frac{D-c-\operatorname{cov}}{s} \cot \theta,
$$

where $A_{s w}$ is the area of the hoop's one leg, $f_{y w}$ is the hoop's yield strength, $c$ is the compression zone's depth, and cov is the concrete cover.

With reference to the concrete mechanism, the following equation was discussed in the cited work:

$$
V_{c}=\alpha \beta \gamma \sqrt{f_{c}^{\prime}}\left(0.8 A_{g}\right),
$$

where the parameter $\alpha$ accounts for the column aspect ratio, the factor $\beta$ is a modified factor that accounts for the longitudinal steel ratio, and $\gamma$ represents the reduction in strength of the concrete shear resisting mechanism with increasing ductility.

Also Kim and Mander [36] reported a deficiency of the model originally proposed by Ghee et al. [8] and verified that the applied integral averaging by the reinforcement term restricts its use only to members with diameter at least four times the spacing of the shear reinforcement. For all other ratios, the formula could be even more than 50\% nonconservative. For this reason, they proposed a corrective coefficient to convert the amount of shear implied by a continuous truss model to the discrete model.

The current ACI 318-M-08 [37] considers a portion of the design shear force to be carried by the concrete shear resisting mechanism, $V_{c}$, with the remainder carried by truss mechanism, $V_{s}$, involving transverse reinforcement. The code proposes the following equation to calculate $V_{c}$ for members subjected to combined shear, moment, and axial compression:

$$
V_{c}=0.17\left(1+\frac{P}{14 A_{g}}\right) \sqrt{f_{c}^{\prime}} b_{w} d .
$$

The transverse reinforcement contribution is also calculated as

$$
V_{s}=\frac{A_{\mathrm{sh}} f_{\mathrm{yh}} d}{s},
$$

where the meaning of various terms has been explained before.
Merta [17] developed a simple shear capacity model of RC circular sections. It was based on the truss analogy by adding an empirical concrete contribution term to the capacity of the shear reinforcement, obtaining finally the following relation:

$$
\begin{aligned}
V= & {\left[3.7 \rho_{l}+0.18+0.08\left(\frac{P}{A_{g}}\right) 0.3\right] k \sqrt{f_{c}^{\prime}} 0.7 A_{g} } \\
& +A_{s w} f_{y w}\left(1.8 n_{t}+\lambda n_{d}-1\right),
\end{aligned}
$$

where $n_{t}$ represents the number of hoops across the crack and is evaluated considering only the hoops outside the compression zone:

$$
n_{t}=\frac{D-c-\operatorname{cov}}{s} \cot \theta
$$

while $\lambda$ is assumed to be equal to 0.53 and $n_{d}$ is given by

$$
n_{d}=\operatorname{INT}\left[\frac{D / 2-\operatorname{cov}}{s} \cot \theta\right]
$$

being $c \cong 0.3 D$. The influence of the main variables on the shear capacity, such as the longitudinal reinforcement ratio $\rho_{l}$, the axial load level $P / A_{g}$, and the shear span-to-depth ratio $a / D$, has been determined empirically, based on a total of 44 pieces of data of circular cross-section specimens without shear reinforcement under monotonic load. The term $0.7 \mathrm{Ag}_{\mathrm{g}}$ represents the section's effective shear area, while $k=1$ if $a / D>2.5$ and 1.25 if $a / D \leq 2.5$.

\section{A Data-Driven Approach for Estimation of Shear Strength of Reinforced Concrete Circular Columns: The Evolutionary Polynomial Regression Paradigm}

Numerical Regression is the most powerful and commonly applied form of regression that provides a solution to the problem of finding the best model to fit the observed data (e.g., fitting a line through a set of points). However, the functional form (linear, exponential, logarithmic, etc.) has to be selected before fitting commences. On the other hand, genetic pogramming uses simple but very powerful artificial intelligence tactics for computer learning inspired by natural evolution to find the appropriate mathematical model to fit a set of points. The computer produces and evolves a whole population of functional expressions based on how closely each of them fits the data. The evolutionary polynomial regression (EPR) is a recently developed hybrid regression method by Giustolisi and Savic [25] that integrates the best features of numerical regression with genetic programming $[39,40]$. An example of the general model structures that EPR can manage is reported in

$$
\begin{aligned}
& \mathbf{Y}=a_{0}+\sum_{j=1}^{m} a_{j} \cdot\left(\mathbf{X}_{1}\right)^{\mathbf{E S}(j, 1)} \cdot \ldots \cdot\left(\mathbf{X}_{k}\right)^{\mathbf{E S}(j, k)} \\
& \cdot f\left(\left(\mathbf{X}_{1}\right)^{\mathbf{E S}(j, k+1)} \cdot \ldots \cdot\left(\mathbf{X}_{k}\right)^{\mathbf{E S}(j, 2 k)}\right),
\end{aligned}
$$


where $m$ is the number of additive terms, $a_{j}$ are numerical parameters to be estimated, $\mathbf{X}_{i}$ are candidate explanatory variables, $\mathbf{E S}(j, z)$ (with $z=1, \ldots, 2 k$ ) is the exponent of the $z$ th input within the $j$ th term in (18), and $f$ is a user-selected function among a set of possible alternatives (including no function selection). The exponents $\mathbf{E S}(j, z)$ are selected from a user-defined set of candidate values. Note that it is recommended to include 0 among such exponents in order to allow EPR to exclude some of the candidate explanatory variables in $\mathbf{X}_{i}$ from those present in the returned models, thus selecting the most influencing input variables on the target prediction.

Starting from a general structure, such as that in (18), the final model expression is obtained through a population based strategy that mimics the evolution of the individuals in nature; it is a combination of a genetic algorithm (GA) [41] paradigm for finding the best exponents to be assigned to each candidate input and a least squares (LS) regression [42], for the identification of the constant values $a_{j}$ [25].

Recently, the EPR has been upgraded to MOGA EPR through the implementation of a search pattern of the best models based on a multiobjective genetic algorithm (MOGA) [43] optimization scheme, being able to find several model expressions maximizing fitness to data and parsimony of mathematical formulations simultaneously [29]. MOGA EPR explores the space of $m$-terms formulas using at least three objectives among the following conflicting ones: (i) maximization of model accuracy, (ii) minimization of the number of model coefficients, and (iii) minimization of the number of actually used model inputs (i.e., whose exponent is not null in the resulting model structure). Based on the Pareto dominance criterion [44], MOGA EPR finally obtains a set of optimal solutions (i.e., the Pareto front) which can be considered as trade-offs between structural complexity and accuracy. MOGA EPR displays the returned formulas, within the Pareto front, as ranked according to their structural complexity; this way, the comparisons among formulas according to different criteria (e.g., selected inputs, structure, etc.) are facilitated, as well as the selection of models suited for different modeling purposes [29].

In particular, this possibility has been exploited in this paper in order to find the best model for the estimation of shear strength of reinforced concrete circular columns. Thus, the first step was to define the MOGA EPR search options (candidate model attributes, candidate exponents for attributes, maximum number of parameters, objective functions, etc.); then, the set of optimal models, with respect to the objective functions, produced by MOGA EPR has been analyzed by considering (i) the model structure with respect to physical insight of the phenomenon at stake; (ii) the similarities and/or recurrent groups of variables within the mathematical structures of the Pareto models; (iii) the generalization performance of models in terms of statistical indicators and mathematical parsimony. Moreover, the returned models have been also evaluated looking at their consistency with existing codes/theories about the physical phenomenon, as described above. All these issues can lead to a quite robust model selection. Figure 2 is illustrative of the decision support framework allowed by MOGA EPR, as here implemented.

The present analyses have been performed using the EPR MOGA-XL v.1 which is a Microsoft Office Excel add-in function freely available at www.hydroinformatics.it, which employs a MOGA optimizer named optimized multiobjective genetic algorithm (OPTIMOGA) [45].

\section{Results and Comparison with Literature and Technical Code Models}

The proposed model has been verified by comparing it to existing ones and to experimental tests. The experimental data herein considered have been obtained from Merta [17], Capon and Cossio [19], Khalifa and Collins [20], Clarke and Birjandi [18], and Kim [38] and include the results of several tests performed by different authors. The test specimens refer to circular columns characterized by six different diameters and having both shear and longitudinal reinforcements. Longitudinal reinforcement consists mainly of high yield bars placed evenly at eight locations round the pitch circle. Shear reinforcement is generally in the form of $6 \mathrm{~mm}$ or $8 \mathrm{~mm}$ mild steel links. The compressive strength of concrete ranges from 13.2 $\mathrm{MPa}$ to $49.3 \mathrm{MPa}$, the stirrup percentage ranges from $0.1 \%$ to $0.45 \%$, the yielding stress of shear reinforcement ranges from $250 \mathrm{MPa}$ to $1728 \mathrm{MPa}$, and the longitudinal steel percentage ranges from $2.2 \%$ to $5.6 \%$.

A total of 61 circular columns have been selected with different geometric and mechanical parameters such as dimension of the section diameter $(D)$, area of concrete $\left(A_{g}\right)$, total cross-section of links at the neutral axis of the section $\left(A_{\mathrm{sh}}\right)$, spacing of links along the member $(s)$, concrete compressive strength $\left(f_{c}\right)$, yield strength of closed links $\left(f_{\mathrm{yh}}\right)$, total area of longitudinal reinforcement $\left(A_{\mathrm{sl}}\right)$, yield strength of longitudinal reinforcement $\left(f_{\mathrm{yl}}\right)$, concrete cover (cov), effective depth $(d)$, and axial compression load $(P)$. The range of datasets is listed in Table 1.

The main objective of this study is to investigate the application of EPR MOGA technique to get possible new formulations of shear strength of circular RC columns able to reproduce the experimental data better than the existing code expressions. In fact the correlation coefficient $R^{2}$ between experimental data and previsions of ACI $318 \mathrm{M}-08$ [37] and BS 8100 [33] are $90.15 \%$ and $76.92 \%$, respectively; thus, there is some room for possible improvements.

Since most of experimental data refer to pure-shear tests, the dependence of shear strength from the axial force $P$ is not investigated. It can be accounted for by adding a term representative of the axial force contribution, as the one proposed in Merta or in technical code models.

4.1. EPR MOGA Search Settings. Bearing in mind what above mentioned about MOGA EPR search paradigm, some compact expressions will be sought for, in terms of both number of parameters and explanatory variables involved. This, in turn, would facilitate their physical interpretation and technical soundness for practical purposes. The base 
TABLE 1: Details and test results of specimens with circular cross-section.

\begin{tabular}{|c|c|c|c|c|c|c|c|c|c|c|c|c|c|}
\hline References & Number & $\begin{array}{c}D \\
{[\mathrm{~mm}]}\end{array}$ & $\begin{array}{c}A_{g} \\
{\left[\mathrm{~mm}^{2}\right]}\end{array}$ & $\begin{array}{c}f_{c} \\
{[\mathrm{MPa}]}\end{array}$ & $\begin{array}{c}\mathrm{cov} \\
{[\mathrm{mm}]}\end{array}$ & $\begin{array}{c}A_{\mathrm{sh}} \\
{\left[\mathrm{mm}^{2}\right]}\end{array}$ & $\begin{array}{c}f_{\mathrm{yh}} \\
{[\mathrm{MPa}]}\end{array}$ & $\begin{array}{c}s \\
{[\mathrm{~mm}]}\end{array}$ & $\begin{array}{c}d \\
{[\mathrm{~mm}]}\end{array}$ & $\begin{array}{c}f_{\mathrm{yl}} \\
{[\mathrm{MPa}]}\end{array}$ & $\begin{array}{c}A_{\mathrm{sl}} \\
{\left[\mathrm{mm}^{2}\right]}\end{array}$ & $\begin{array}{c}P \\
{[\mathrm{kN}]}\end{array}$ & $\begin{array}{c}V_{\text {test }} \\
{[\mathrm{kN}]}\end{array}$ \\
\hline & $\mathrm{M} 1 / 2$ & 152 & 18145.839 & 28 & 10 & 5624 & 300 & 100 & 121.6 & 500 & 39920.846 & 0 & 45.0 \\
\hline & $\mathrm{M} 1 / 3$ & 152 & 18145.839 & 28 & 10 & 5624 & 300 & 100 & 121.6 & 500 & 39920.846 & 0 & 46.0 \\
\hline & $\mathrm{M} 1 / 4$ & 152 & 18145.839 & 28 & 10 & 5624 & 300 & 100 & 121.6 & 500 & 39920.846 & 0 & 38.0 \\
\hline & $11-1$ & 300 & 70685.835 & 24.1 & 20 & 9900 & 300 & 150 & 240 & 500 & 395840.67 & 0 & 186.0 \\
\hline & $11-2$ & 300 & 70685.835 & 24.1 & 20 & 9900 & 300 & 150 & 240 & 500 & 395840.67 & 0 & 188.0 \\
\hline & $12-1$ & 300 & 70685.835 & 23.8 & 20 & 10125 & 300 & 75 & 240 & 500 & 395840.67 & 0 & 211.0 \\
\hline & $12-2$ & 300 & 70685.835 & 23.8 & 20 & 10125 & 300 & 75 & 240 & 500 & 395840.67 & 0 & 239.0 \\
\hline & $13-1$ & 300 & 70685.835 & 48.4 & 20 & 9900 & 300 & 150 & 240 & 500 & 395840.67 & 0 & 227.0 \\
\hline & $13-2$ & 300 & 70685.835 & 48.4 & 20 & 9900 & 300 & 150 & 240 & 500 & 395840.67 & 0 & 228.0 \\
\hline & $14-1$ & 300 & 70685.835 & 50.5 & 20 & 10125 & 300 & 75 & 240 & 500 & 395840.67 & 0 & 279.0 \\
\hline & $14-2$ & 300 & 70685.835 & 50.5 & 20 & 10125 & 300 & 75 & 240 & 500 & 395840.67 & 0 & 288.0 \\
\hline & $15-1$ & 300 & 70685.835 & 24.3 & 20 & 9900 & 300 & 150 & 240 & 500 & 254469 & 0 & 145.0 \\
\hline & $15-2$ & 300 & 70685.835 & 24.3 & 20 & 9900 & 300 & 150 & 240 & 500 & 254469 & 0 & 148.0 \\
\hline & $16-1$ & 300 & 70685.835 & 46.7 & 20 & 9900 & 300 & 150 & 240 & 500 & 254469 & 0 & 185.0 \\
\hline & $16-2$ & 300 & 70685.835 & 46.7 & 20 & 9900 & 300 & 150 & 240 & 500 & 254469 & 0 & 186.0 \\
\hline & $17-1$ & 300 & 70685.835 & 23.7 & 20 & 5850 & 300 & 150 & 240 & 500 & 162577.42 & 0 & 117.0 \\
\hline & $17-2$ & 300 & 70685.835 & 23.7 & 20 & 5850 & 300 & 150 & 240 & 500 & 162577.42 & 0 & 115.0 \\
\hline & $19-1$ & 300 & 70685.835 & 26.6 & 20 & 5850 & 300 & 150 & 240 & 500 & 254469 & 0 & 113.0 \\
\hline & $19-2$ & 300 & 70685.835 & 26.6 & 20 & 5850 & 300 & 150 & 240 & 500 & 254469 & 0 & 129.0 \\
\hline & $20-1$ & 300 & 70685.835 & 49.3 & 20 & 5850 & 300 & 150 & 240 & 500 & 254469 & 0 & 149.0 \\
\hline & $20-2$ & 300 & 70685.835 & 49.3 & 20 & 5850 & 300 & 150 & 240 & 500 & 254469 & 0 & 137.0 \\
\hline & $21-1$ & 300 & 70685.835 & 22.2 & 20 & 5850 & 300 & 150 & 240 & 500 & 395840.67 & 0 & 131.0 \\
\hline & $21-2$ & 300 & 70685.835 & 22.2 & 20 & 5850 & 300 & 150 & 240 & 500 & 395840.67 & 0 & 151.0 \\
\hline & $22-1$ & 300 & 70685.835 & 45.5 & 20 & 5850 & 300 & 150 & 240 & 500 & 395840.67 & 0 & 163.0 \\
\hline \multirow[t]{25}{*}{ Clarke and Birjandi [18] } & $22-2$ & 300 & 70685.835 & 45.5 & 20 & 5850 & 300 & 150 & 240 & 500 & 395840.67 & 0 & 164.0 \\
\hline & $23-1$ & 300 & 70685.835 & 25.1 & 20 & 5850 & 300 & 150 & 240 & 500 & 162577.42 & 0 & 101.0 \\
\hline & $23-2$ & 300 & 70685.835 & 25.1 & 20 & 5850 & 300 & 150 & 240 & 500 & 162577.42 & 0 & 103.0 \\
\hline & $24-1$ & 300 & 70685.835 & 48.9 & 20 & 5850 & 300 & 150 & 240 & 500 & 162577.42 & 0 & 114.0 \\
\hline & $24-2$ & 300 & 70685.835 & 48.9 & 20 & 5850 & 300 & 150 & 240 & 500 & 162577.42 & 0 & 128.0 \\
\hline & $25-1$ & 300 & 70685.835 & 24.3 & 20 & 5850 & 300 & 150 & 240 & 500 & 254469 & 0 & 98.0 \\
\hline & $25-2$ & 300 & 70685.835 & 24.3 & 20 & 5850 & 300 & 150 & 240 & 500 & 254469 & 0 & 122.0 \\
\hline & $26-1$ & 300 & 70685.835 & 47.1 & 20 & 5850 & 300 & 150 & 240 & 500 & 254469 & 0 & 114.0 \\
\hline & $26-2$ & 300 & 70685.835 & 47.1 & 20 & 5850 & 300 & 150 & 240 & 500 & 254469 & 0 & 150.0 \\
\hline & $27-1$ & 300 & 70685.835 & 22.8 & 20 & 5850 & 300 & 150 & 240 & 500 & 395840.67 & 0 & 125.0 \\
\hline & $27-2$ & 300 & 70685.835 & 22.8 & 20 & 5850 & 300 & 150 & 240 & 500 & 395840.67 & 0 & 134.0 \\
\hline & $28-1$ & 300 & 70685.835 & 22.8 & 20 & 5850 & 300 & 150 & 240 & 500 & 395840.67 & 0 & 158.0 \\
\hline & $28-2$ & 300 & 70685.835 & 45.3 & 20 & 5850 & 300 & 150 & 240 & 500 & 395840.67 & 0 & 175.0 \\
\hline & $37-1$ & 300 & 70685.835 & 43.9 & 20 & 9900 & 300 & 150 & 240 & 500 & 395840.67 & 270.9 & 232.0 \\
\hline & $37-2$ & 300 & 70685.835 & 43.9 & 20 & 9900 & 300 & 150 & 240 & 500 & 395840.67 & 0 & 218.0 \\
\hline & $38-1$ & 300 & 70685.835 & 36.1 & 20 & 9900 & 300 & 150 & 240 & 500 & 395840.67 & 270.9 & 209.0 \\
\hline & $38-2$ & 300 & 70685.835 & 36.1 & 20 & 9900 & 300 & 150 & 240 & 500 & 395840.67 & 0 & 206.0 \\
\hline & $39-1$ & 300 & 70685.835 & 36.3 & 20 & 9900 & 300 & 150 & 240 & 500 & 395840.67 & 270.6 & 217.2 \\
\hline & $39-2$ & 300 & 70685.835 & 36.3 & 20 & 9900 & 300 & 150 & 240 & 500 & 395840.67 & 0 & 197.0 \\
\hline & $40-1$ & 300 & 70685.835 & 34.1 & 20 & 9900 & 300 & 150 & 240 & 500 & 395840.67 & 274.1 & 225.0 \\
\hline & $40-2$ & 300 & 70685.835 & 34.1 & 20 & 9900 & 300 & 150 & 240 & 500 & 395840.67 & 0 & 183.0 \\
\hline & $43-1$ & 500 & 196349.54 & 37.8 & 20 & 9800 & 300 & 140 & 400 & 500 & 510508.81 & 0 & 313.0 \\
\hline & $43-2$ & 500 & 196349.54 & 37.8 & 20 & 9800 & 300 & 140 & 400 & 500 & 510508.81 & 0 & 366.0 \\
\hline & $44-1$ & 500 & 196349.54 & 32.9 & 20 & 9800 & 300 & 140 & 400 & 500 & 510508.81 & 0 & 301.0 \\
\hline & $44-2$ & 500 & 196349.54 & 32.9 & 20 & 9800 & 300 & 140 & 400 & 500 & 510508.81 & 0 & 329.0 \\
\hline
\end{tabular}


TABle 1: Continued.

\begin{tabular}{|c|c|c|c|c|c|c|c|c|c|c|c|c|c|}
\hline References & Number & $\begin{array}{c}D \\
{[\mathrm{~mm}]}\end{array}$ & $\begin{array}{c}A_{g} \\
{\left[\mathrm{~mm}^{2}\right]}\end{array}$ & $\begin{array}{c}f_{c} \\
{[\mathrm{MPa}]}\end{array}$ & $\begin{array}{c}\mathrm{cov} \\
{[\mathrm{mm}]}\end{array}$ & $\begin{array}{c}A_{\mathrm{sh}} \\
{\left[\mathrm{mm}^{2}\right]}\end{array}$ & $\begin{array}{c}f_{\mathrm{yh}} \\
{[\mathrm{MPa}]}\end{array}$ & $\begin{array}{c}s \\
{[\mathrm{~mm}]}\end{array}$ & $\begin{array}{c}d \\
{[\mathrm{~mm}]}\end{array}$ & $\begin{array}{c}f_{\mathrm{yl}} \\
{[\mathrm{MPa}]}\end{array}$ & $\begin{array}{c}A_{\mathrm{sl}} \\
{\left[\mathrm{mm}^{2}\right]}\end{array}$ & $\begin{array}{c}P \\
{[\mathrm{kN}]}\end{array}$ & $\begin{array}{c}V_{\text {test }} \\
{[\mathrm{kN}]}\end{array}$ \\
\hline \multirow{4}{*}{ Khalifa and Collins [20] } & SC1 & 445 & 155528.47 & 19.3 & 23 & 6675 & 410 & 150 & 356 & 516 & 589452.91 & 1017 & 324.0 \\
\hline & SC2 & 445 & 155528.47 & 23 & 23 & 20025 & 510 & 150 & 356 & 516 & 589452.91 & 1083 & 478.0 \\
\hline & SC3 & 445 & 155528.47 & 24.5 & 23 & 30037.5 & 510 & 150 & 356 & 516 & 589452.91 & 1085 & 578.0 \\
\hline & SC4 & 445 & 155528.47 & 26.5 & 23 & 20025 & 430 & 150 & 356 & 516 & 589452.91 & 1050 & 456.0 \\
\hline \multirow{4}{*}{$\begin{array}{l}\text { Merta [17] } \\
\text { Capon and Cossio [19] }\end{array}$} & 1 & 400 & 125663.71 & 42.2 & 0 & 5760 & 700 & 60 & 320 & 700 & 471238.9 & 0 & 430.0 \\
\hline & 2 & 400 & 125663.71 & 42.2 & 0 & 5760 & 700 & 60 & 320 & 700 & 471238.9 & 0 & 432.0 \\
\hline & F12.5 & 251 & 49480.87 & 13.2 & 15 & 6275 & 250 & 250 & 200.8 & 400 & 152401.08 & 0 & 59.5 \\
\hline & F12.5 & 251 & 49480.87 & 13.2 & 15 & 6275 & 250 & 125 & 200.8 & 400 & 152401.08 & 0 & 82.0 \\
\hline \multirow{5}{*}{ Kim [38] } & YJC200R & 445 & 155528.47 & 40.4 & 25 & 14240 & 445 & 200 & 356 & 460 & 600339.9 & 0 & 323.0 \\
\hline & YJC150R & 445 & 155528.47 & 36 & 25 & 14017.5 & 445 & 150 & 356 & 460 & 600339.9 & 0 & 411.0 \\
\hline & YJC100R & 445 & 155528.47 & 36 & 25 & 14240 & 445 & 100 & 356 & 460 & 600339.9 & 0 & 479.0 \\
\hline & YJC200W & 445 & 155528.47 & 33.2 & 25 & 445 & 1728 & 200 & 356 & 460 & 600339.9 & 0 & 315.0 \\
\hline & YJC100W & 445 & 155528.47 & 36 & 25 & 0 & 1728 & 100 & 356 & 460 & 0 & 0 & 434.0 \\
\hline
\end{tabular}
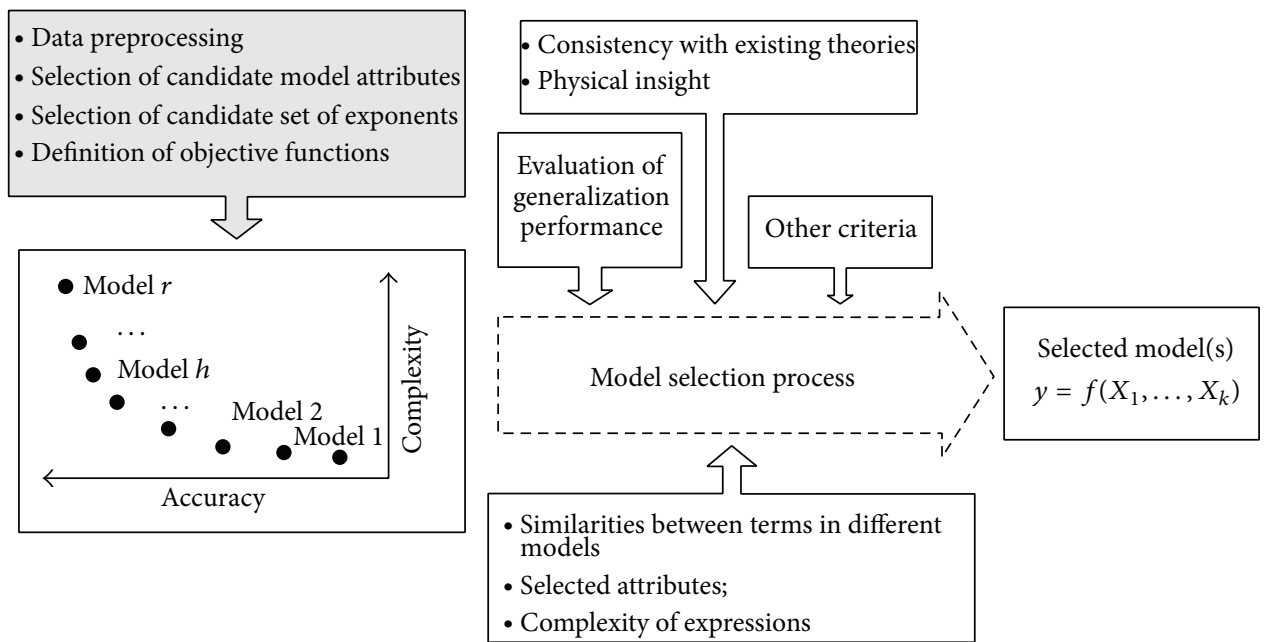

FIGURE 2: Decision support framework for model selection based on EPR MOGA paradigm.

model structure reported in (18) is adopted with no function $f$ selected; accordingly, each additive monomial term is assumed to be a combination of the input variables raised to relevant exponents.

The candidate explanatory variables (i.e., model inputs, see Table 1) are $D, d, A_{g}, A_{\mathrm{sh}}, s, A_{\mathrm{sl}}, f_{c}$, and $f_{\mathrm{yh}}$; they have been selected by both looking at the existing literature and performing some preliminary sensitivity analyses. The candidate exponents are $[-1,-0.5,-2 / 3,0,0.5,2 / 3,1]$ in order to represent both linear and nonlinear relationships as well as direct/inverse dependence between candidate input(s) and output (i.e., model target). The maximum number of additive term in the final expressions is assumed to be $m=3$, so that could be easily compared with the existing formulations.

4.2. Selection of EPR MOGA Models. Two EPR MOGA runs were finally selected, characterized by different sets of exponents and by the same set of input variables $(D$, $\left.d, A_{g}, A_{\mathrm{sh}}, s, A_{\mathrm{sl}}, f_{c}, f_{\mathrm{yh}}\right)$. Models obtained from EPR
MOGA runs show different number of terms and explanatory variables as well as different accuracy. The model selection procedure takes into account some key aspects: agreement with experimental data, model parsimony and consistency with both physical insight about the shear behavior of circular RC columns, and previous building code formulations. From among all models obtained, the following formulas have been selected (the unit for $V_{\mathrm{Rd}}$ is $[\mathrm{N}]$ and all the mechanical and geometrical quantities are expressed in $[\mathrm{N}]$ and $[\mathrm{mm}]$ resp.):

$$
\begin{gathered}
V_{\mathrm{Rd}}=4.1525 d \rho_{h} f_{\mathrm{yh}}+0.13552 A_{g} \sqrt{f_{c}} \sqrt{\rho_{l}}, \\
\left(R^{2}=95.61 \%\right), \\
V_{\mathrm{Rd}}=+7.121 \sqrt{A_{g} f_{\mathrm{yh}}}+0.043393 \rho_{h} A_{g} \sqrt{f_{\mathrm{yh}} f_{c}} \\
+0.013495 \rho_{l} A_{g} \sqrt{D}, \quad\left(R^{2}=97.84 \%\right),
\end{gathered}
$$




$$
\begin{aligned}
V_{\mathrm{Rd}}= & 1.0737 d \frac{A_{\mathrm{sh}}}{s} f_{\mathrm{yh}}+0.25274 D d \sqrt{f_{c}}, \\
V_{\mathrm{Rd}}= & 0.98243 d \frac{A_{\mathrm{sh}}}{s} f_{\mathrm{yh}}+0.086185 D d \sqrt{f_{c}} \\
& \times\left(1+56.2 \frac{A_{\mathrm{sl}}}{D d}\right), \quad\left(R^{2}=95.98 \%\right), \\
V_{\mathrm{Rd}}= & 1.0072 d \frac{A_{\mathrm{sh}}}{s} f_{\mathrm{yh}}+2.3931 d D\left(\frac{A_{\mathrm{sl}}}{A_{g}}\right) f_{c}^{2 / 3} \\
& +0.098766 D d \sqrt{f_{c}}, \quad\left(R^{2}=95.39 \%\right),
\end{aligned}
$$

where $\rho_{h}=\left(A_{\mathrm{sh}} /(s D)\right) \cdot 100$ and $\rho_{l}=\left(A_{\mathrm{sl}} / A_{g}\right) \cdot 100$.

Although the EPR MOGA search for models is based on the coefficient of determination (COD) as defined in [25], model performances are reported in terms of $R^{2}$ in order to allow a straight comparison with code provisions $[33,37]$ and alternative formulations $[17,18]$.

Expressions (19)-(22) are obtained by considering the set of exponents $[-1,-0.5,0,0.5,1]$, while in expression (23) exponents belonging to the set $[-1,-2 / 3,-0.5,0,0.5,2 / 3,1]$ are assumed.

Proposed models are compared to ACI 318-M-08 [37], BS 8100 [33] predictions, and the two existing models of Clarke and Birjandi [18] and Merta [17]; the corresponding correlation coefficients $R^{2}$ with respect to the experimental data herein considered are, respectively, equal to $90.15 \%, 76.92 \%$ $96.23 \%$, and $95.29 \%$. Figure 3 depicts the shear strength as predicted by the EPR models (19)-(23) versus the experimental results; similarly, Figure 4 shows the same graphs with reference to the code formulations and the literature models mentioned above. As expected from the values of the coefficients $R^{2}$, expression (20) provides the smallest scatter in the plot of the experimental/theoretical ultimate shear strength of specimens; however, the complexity of expression (20) discourages its use for practical purposes. Formulas (19), (22), and (23) provide predictions similar to the Clarke and Birjandi ones and are anyway slightly better than the Merta ones.

Formula (23) predictions are more conservative than Clarke and Birjandi ones, with a similar or often closer correlation with experimental data. It is also evident that the ACI 318-M-08 and BS 8100 predictions, which neglect the influence of the longitudinal reinforcement contribution, are highly conservative. In fact, BS 8100 predictions in Figure 4 are calculated by adopting $\cot \theta=2.5$; otherwise, by putting $\cot \theta=1$ more conservative values of shear strength are obtained.

In expressions (19) and (20), the physical consistency of the problem is not easily recognizable, while on the contrary models (21)-(23) are similar to the building code formulations and thus preserve the physical insight into the problem. In particular, (21) differs from the ACI 318-M-08 [37] prediction only for the multiplying factor 0.25274 of the concrete contribution which is higher than the code one, allowing a better agreement with the experimental values of shear capacity.

Equation (21) implies that the shear capacity of the member is the sum of the shear carried by concrete and transverse reinforcement; nevertheless, according to this approach, which is consistent with code formulation, a maximum correlation coefficient equal to $91.53 \%$ can be obtained. On the contrary, in the other proposed models also the contribution of longitudinal reinforcement is accounted for, allowing gaining higher values of the correlation coefficient.

In particular in (22) and (23) the concrete and transverse reinforcement contributions preserve the same shapes as ACI 318-M-08, while the longitudinal reinforcement contribution is function of the concrete tensile strength, which in fact is proportional to $\sqrt{f_{c}}$ according to ACI 318-M-08 [37] or Vecchio and Collins [13] and to $f_{c}^{2 / 3}$ according to Italian code [46]. Moreover, the longitudinal reinforcement contribution in (23) is similar to the Italian code expression valid in the case of rectangular sections in the absence of stirrups [46]. These results suggest that the third contribution to the shear capacity of circular sections is due to the dowel effect; longitudinal reinforcement affects the strain state of the element and the crack widths, influencing the concrete contribution by aggregate interlock to the shear strength.

One of the most significant advantages of EPR is that this technique is capable of representing the relationship between the parameters in the form of a polynomial expression, so parametric studies can be conducted to investigate the contribution of different parameters involved and to assess whether the developed model is able to capture the physical relationships between various parameters of the system. In the context of the present study, this also gives an insight to the user about the degree of influence that different parameters can have on the shear of circular sections. To achieve this, a parametric study is carried out where all parameters are set to their mean values except one that is changed from its minimum to maximum values in the testing set. The results of the parametric study for the shear strength model of circular elements are shown in Figure 5 with reference to code provisions (ACI 318-M-08, BS 8100) and (20), (22). By adopting formula (23), graphs quite similar to formula (22) ones are obtained, which are omitted here for sake of brevity.

The results show that the shear strength increases as the concrete compressive strength, the amount of transverse reinforcement, the amount of longitudinal reinforcement, and the section diameter increase. In particular, the section diameter has a significant influence on the value of the shear strength. This is consistent with the expected shear behavior of circular sections. It emerges that the EPR models, directly developed using experimental data, are able to capture the various aspects of shear behavior of circular section correctly and with higher accuracy than exiting technical codes. Moreover, differently from ACI 318-M-08 and BS 8100 predictions, the proposed EPR models can also capture the influence of longitudinal reinforcement on the shear strength. In fact, according to the theoretical models, shear strength should be proportional to the longitudinal 

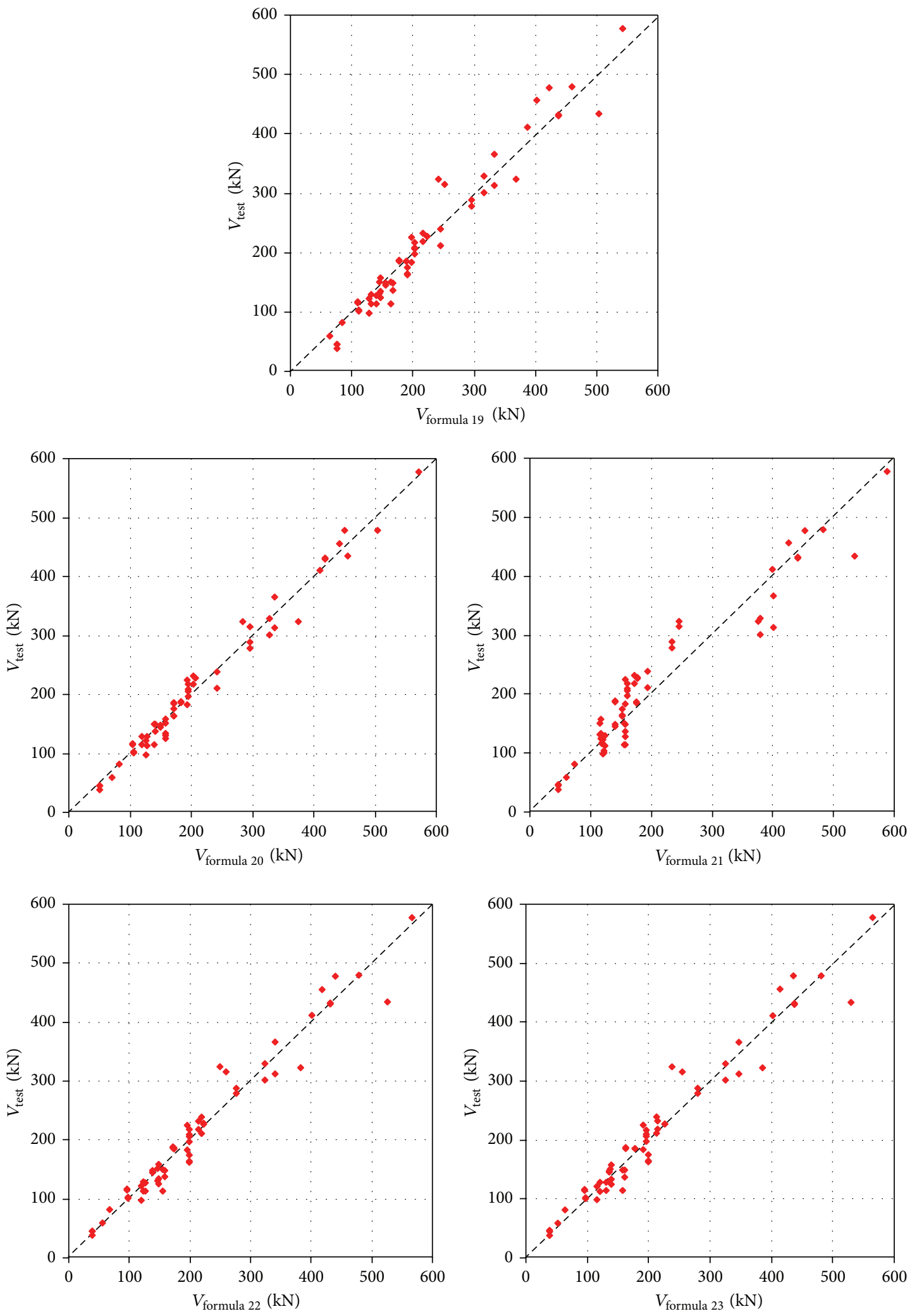

FIGURE 3: Shear strength of circular section members with shear reinforcement: EPR models. 

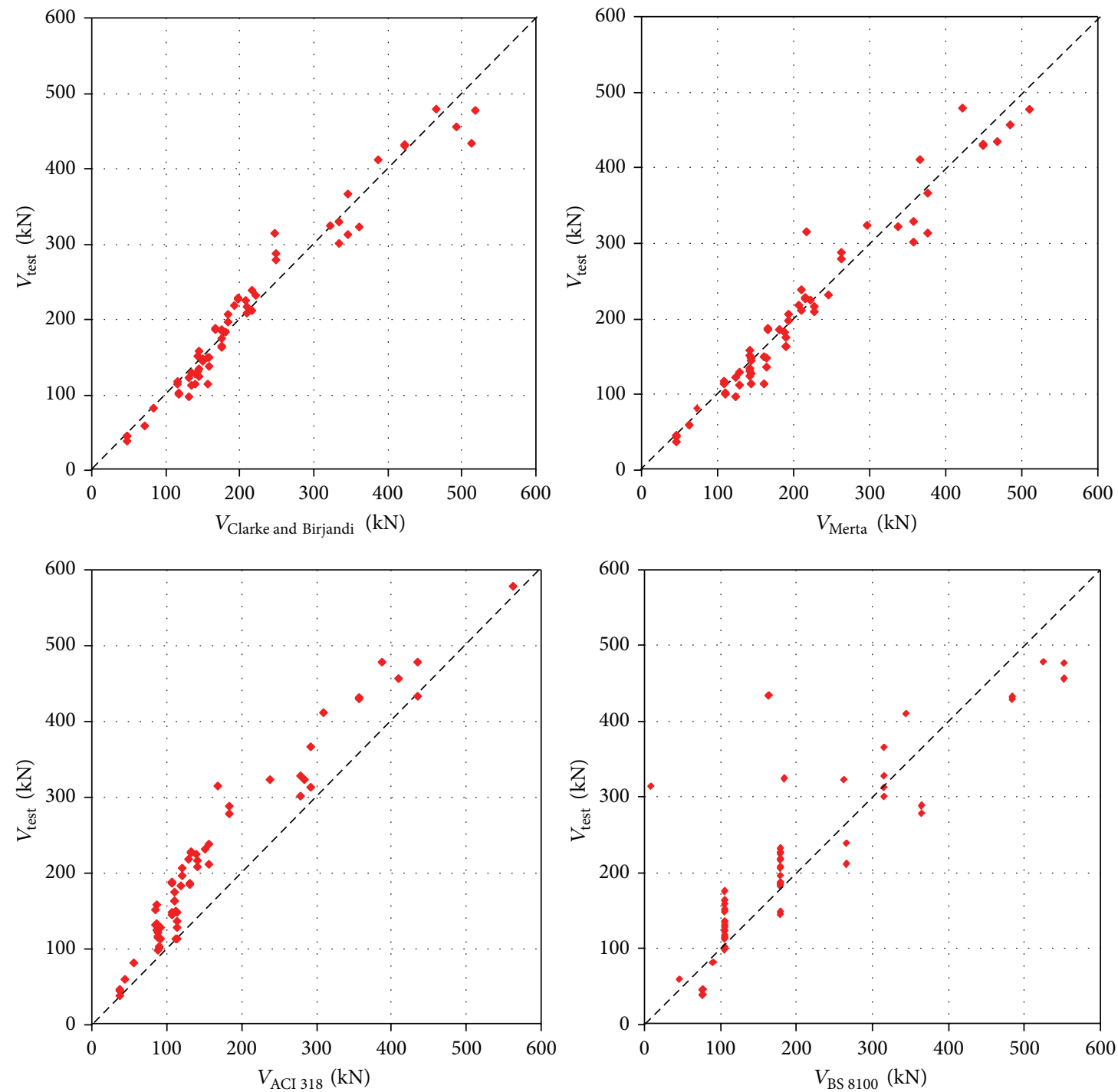

FIGURE 4: Shear strength of circular section members with shear reinforcement: code and literature models.

reinforcement ratio; this is due to the circumstance that as the longitudinal reinforcement ratio decreases, flexural stresses and strains in concrete increase, thus leading to larger crack widths; in addition, dowel action is weakened due to the low longitudinal reinforcement ratio. So the proposed models are coherent with this mechanical behavior.

The above considerations clearly indicate that the proposed models (see (22) and (23)) improve the prediction of the shear capacity preserving the physical insight into the problem; moreover, they represent sufficiently conservative design equations and their simplicity makes them suitable for incorporation in technical codes.

\section{Conclusions}

In the present paper, new formulas for calculating the shear strength of RC circular columns have been proposed. Differently from standard approaches, they are obtained by EPR. In the EPR approach, no preprocessing of the data is required and there is no need for normalization or scaling of the data. The efficiency of such approach has been tested by using experimental data of 61 circular RC elements reported in technical literature. The considered inputs are dimension of the section diameter, area of concrete, total cross-section of links at the neutral axis of the section, spacing of links along the member, concrete compressive strength, yield strength of closed links, total area of longitudinal reinforcement, yield strength of longitudinal reinforcement, and effective depth. Models obtained from EPR MOGA runs show different number of terms and explanatory variables as well as different accuracy. Among all the proposed models, the selected ones provide good predictions, particularly with respect to the code ones. The increased accuracy descends from including the contribution of the dowel effect exercised by the longitudinal reinforcement in the expression of the shear strength. 

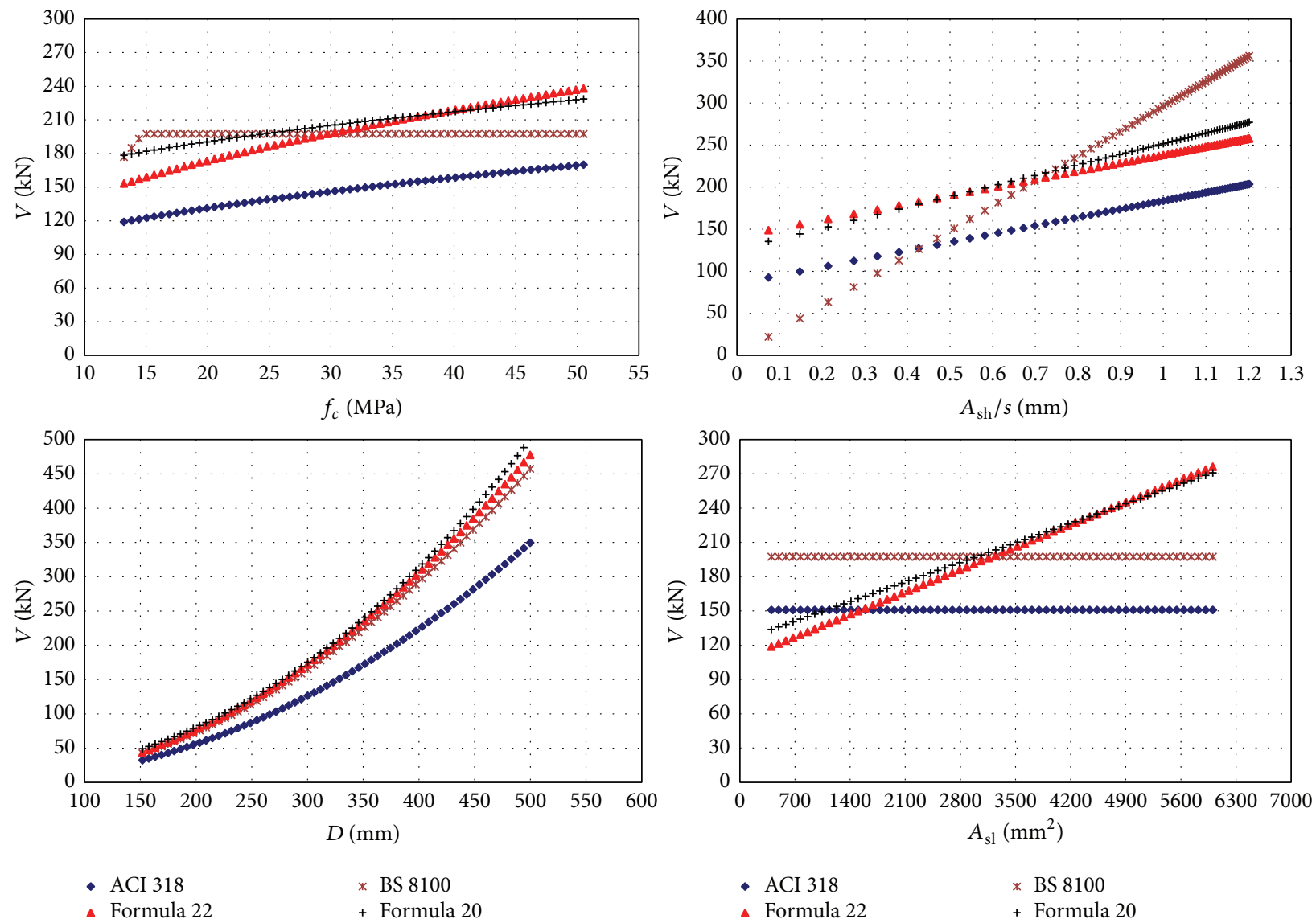

FIGURE 5: Results of the parametric study conducted on the EPR and code models.

A parametric study was also conducted to evaluate the effects of different parameters on the shear strength of circular elements and to verify if the developed models can represent the physical relationships between the contributing parameters. Comparison of the results shows that the developed EPR models provide very accurate predictions for the shear strength of circular sections. They can capture and represent various aspects of shear behavior directly from experimental data. The developed models present a structured and transparent representation of the system, allowing a physical interpretation of the problem that gives the user an insight into the relationship between the mechanical behavior and various contributing parameters. From a practical point of view, the EPR models presented in this paper provide very accurate results and are easy to use.

\section{Conflict of Interests}

The authors declare that there is no conflict of interests regarding the publication of this paper.

\section{References}

[1] A. Fiore, D. Foti, P. Monaco, D. Raffaele, and G. Uva, "An approximate solution for the rheological behavior of nonhomogeneous structures changing the structural system during the construction process," Engineering Structures, vol. 46, pp. 631-642, 2013.

[2] A. Fiore, G. Marano, and P. Monaco, "Earthquake-induced lateral-torsional pounding between two equal height multistorey buildings under multiple bi-directional ground motions," Advances in Structural Engineering, vol. 16, no. 5, pp. 845-865, 2013.

[3] A. Fiore, P. Monaco, and D. Raffaele, "Viscoelastic behaviour of non-homogeneous variable-section beams with post-poned restraints," Computers and Concrete, vol. 9, no. 5, pp. 357-374, 2012.

[4] A. Fiore and P. Monaco, "Analysis of the seismic vulnerability of the "Quinto Orazio Flacco" school in Bari (Italy)," Ingegneria Sismica, vol. 2011, no. 1, pp. 43-62, 2011.

[5] A. Fiore and P. Monaco, "Earthquake-induced pounding between the main buildings of the "Quinto Orazio Flacco" school," Earthquake and Structures, vol. 1, no. 4, pp. 371-390, 2010.

[6] A. Fiore and P. Monaco, "POD-based representation of the alongwind equivalent static force for long-span bridges," Wind and Structures, vol. 12, no. 3, pp. 239-257, 2009.

[7] M. M. Tahir, P. N. Shek, A. Sulaiman, and C. S. Tan, "Experimental investigation of short cruciform columns using universal beam sections," Construction and Building Materials, vol. 23, no. 3, pp. 1354-1364, 2009. 
[8] A. B. Ghee, M. J. N. Priestley, and T. Paulay, "Seismic shear strength of circular reinforced concrete columns," ACI Structural Journal, vol. 86, no. 1, pp. 45-59, 1989.

[9] M. J. N. Priestley, R. Verma, and Y. Xiao, "Seismic shear strength of reinforced concrete columns," ASCE: Journal of Structural Engineering, vol. 120, no. 8, pp. 2310-2329, 1994.

[10] Y.-L. Wong, T. Paulay, and M. J. N. Priestley, "Response of circular reinforced concrete columns to multi-directional seismic attack," ACI Structural Journal, vol. 90, no. 2, pp. 180191, 1993.

[11] M. J. Kowalsky and M. J. N. Priestley, "Improved analytical model for shear strength of circular reinforced concrete columns in seismic regions," ACI Structural Journal, vol. 97, no. 3, pp. 388-396, 2000.

[12] M. P. Collins, E. C. Bentz, and Y. J. Kim, "Shear strength of circular reinforced concrete columns," in S. M. Uzumeri Symposium: Behavior and Design of Concrete Structures for Seismic Performance, pp. 45-86, ACI, Farmington Hills, Mich, USA, 2002.

[13] F. J. Vecchio and M. P. Collins, "The modified compressionfield theory for reinforced concrete elements subjected to shear," Journal of the American Concrete Institute, vol. 83, no. 2, pp. 219231, 1986.

[14] E. C. Bentz, F. J. Vecchio, and M. P. Collins, "Simplified modified compression field theory for calculating shear strength of reinforced concrete elements," ACI Structural Journal, vol. 103, no. 4, pp. 614-624, 2006.

[15] American Association of State Highway and Transportation Official, AASHTO LRFD Bridge Design Specifications, 4th edition, 2007.

[16] J. Turmo, G. Ramos, and A. C. Aparicio, "Shear truss analogy for concrete members of solid and hollow circular cross section," Engineering Structures, vol. 31, no. 2, pp. 455-465, 2009.

[17] I. Merta, "Shear strength model of reinforced concrete circular cross-section members," in Vortrag : Third International Conference on Structural Engineering Mechanics and Computation, Cape Town, South Africa; Recent Developments in Structural Engineering, Mechanics and Computation, A. Zingoni, Ed., Millpress Science Publishers, Rotterdam, The Netherlands, 2007.

[18] J. L. Clarke and F. K. Birjandi, "The behaviour of reinforced concrete circular sections in shear," The Structural Engineer, vol. 71, no. 5, pp. 73-81, 1993.

[19] M. J. F. Capon and R. D. Cossio, "Diagonal tension in concrete members of circular section," Tech. Rep. 466, Portland Cement Association, Foreign Literature Study, 1965.

[20] J. U. Khalifa and M. P. Collins, "Circular reinforced concrete members subjected to shear," Publication 81-08, Department of Civil Engineering, University of Toronto, 1981.

[21] Y. Nagato, Shear Strength of ReinforcedConcrete Members with Circular Cross-Section, Federal University of Rio de Janeiro.

[22] M. J. N. Priestley, F. Seible, and M. Calvi, Seismic Design and Retrofit of Bridges, John Wiley \& Sons, New York, NY, USA, 1996.

[23] J. H. Lee, S. H. Ko, and J. H. Choi, "Shear strength and capacity protection of RC bridge columns," in Proceedings of ANCER 2004, Hawaii, Hawaii, USA, 2004.

[24] U. G. Jensen and L. C. Hoang, "Shear strength prediction of circular RC members by the crack sliding model," Magazine of Concrete Research, vol. 61, no. 9, pp. 691-703, 2009.
[25] O. Giustolisi and D. A. Savic, "A symbolic data-driven technique based on evolutionary polynomial regression," Journal of Hydroinformatics, vol. 8, no. 3, pp. 207-222, 2006.

[26] L. Berardi, Z. Kapelan, O. Giustolisi, and D. A. Savic, "Development of pipe deterioration models for water distribution systems using EPR," Journal of Hydroinformatics, vol. 10, no. 2, pp. 113-126, 2008.

[27] A. Doglioni, D. Mancarella, V. Simeone, and O. Giustolisi, "Inferring groundwater system dynamics from hydrological time-series data," Hydrological Sciences Journal, vol. 55, no. 4, pp. 593-608, 2010.

[28] A. Fiore, L. Berardi, and G. C. Marano, "Predicting torsional strength of RC beams by using Evolutionary Polynomial Regression," Advances in Engineering Software, vol. 47, no. 1, pp. 178-187, 2012.

[29] O. Giustolisi and D. A. Savic, "Advances in data-driven analyses and modelling using EPR-MOGA," Journal of Hydroinformatics, vol. 11, no. 3-4, pp. 225-236, 2009.

[30] E. Mörsch, Der Eisenbetonbau-Seine Theorie und Anwendung, Konrad Wittwer, Stuttgart, Germany, 1922.

[31] M. P. Nielsen, Limit Analysis and Concrete Plasticity, PrenticeHall Series in Civil Engineering, Prentice-Hall, Englewood Cliffs, NJ, USA, 1984.

[32] "Eurocode 2: design of concrete structures, prEN , 1992-1-1, draft for stage 49," European Standard, Commission of the European Communities, European Committee for Standardization, 2002.

[33] BS 8100, Structural Use of Concrete: Part I: Code of Practice for Design and Construction, British Standards Institution, London, UK, 1985.

[34] "Steel, concrete and composite bridges, part 4: code of practice for design of concrete bridges," BS 5400, British Standards Institution, London, UK, 1990.

[35] A. N. Dancygier, "Shear carried by transverse reinforcement in circular RC elements," Journal of Structural Engineering, vol. 127, no. 1, pp. 81-83, 2001.

[36] J. H. Kim and J. B. Mander, "Theoretical shear strength of concrete columns due to transverse steel," Journal of Structural Engineering, vol. 131, no. 1, pp. 197-199, 2005.

[37] ACI 318-M-08. Building Code Requirements for Structural Concrete (ACI 318M-08) and Commentary, American Concrete Institute, 2008.

[38] Y. J. Kim, The shear response of circular columns reinforced with high strength spirals [M.S. thesis], Department of Civil Engineering, University of Toronto, 2000.

[39] G. C. Marano, R. Greco, G. Quaranta, A. Fiore, J. Avakian, and D. Cascella, "Parametric identification of nonlinear devices for seismic protection using soft computing techniques," Advanced Materials Research, vol. 639-640, no. 1, pp. 118-129, 2013.

[40] G. Quaranta, A. Fiore, and G. C. Marano, "Optimum design of prestressed concrete beams using constrained differential evolution algorithm," Structural and Multidisciplinary Optimization, vol. 49, no. 3, pp. 441-453, 2014.

[41] J. H. Holland, Adaptation in Natural and Artificial Systems, The University of Michigan Press, Ann Arbor, Mich, USA, 1975.

[42] N. R. Draper and H. Smith, Applied Regression Analysis, John Wiley \& Sons, New York, NY, USA, 1998.

[43] D. E. Goldberg, Genetic Algorithms in Search, Optimization and Machine Learning, Addison-Wesley, London, UK, 1989. 
[44] V. Pareto, Cours D'Economie Politique. Rouge and Cic, Vol. I and II, Lausanne, Switzerland, 1896.

[45] D. Laucelli and O. Giustolisi, "Scour depth modelling by a multiobjective evolutionary paradigm," Environmental Modelling and Software, vol. 26, no. 4, pp. 498-509, 2011.

[46] D. M. LL. PP. 9 Gennaio 1996, Norme tecniche per il calcolo, l'esecuzione ed il collaudo delle strutture in cemento armato normale e precompresso e per le strutture metalliche, 1996 (Italian). 

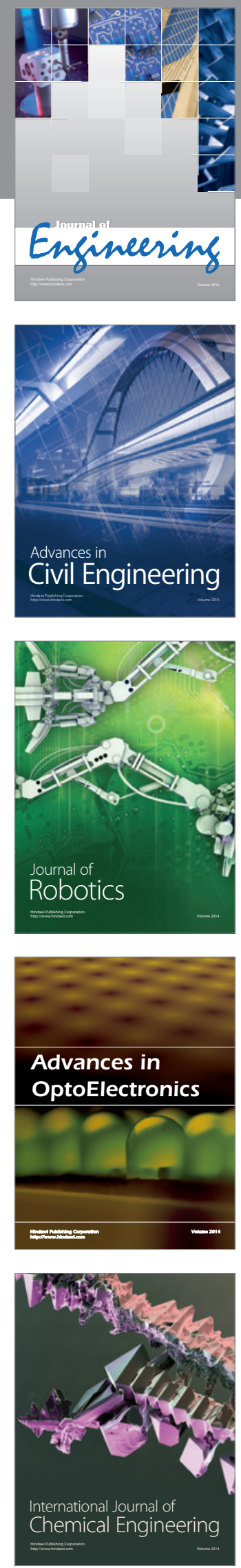

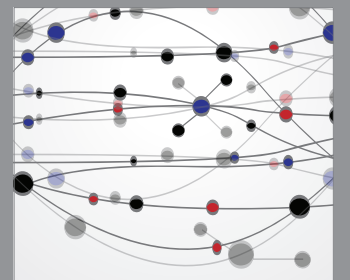

The Scientific World Journal
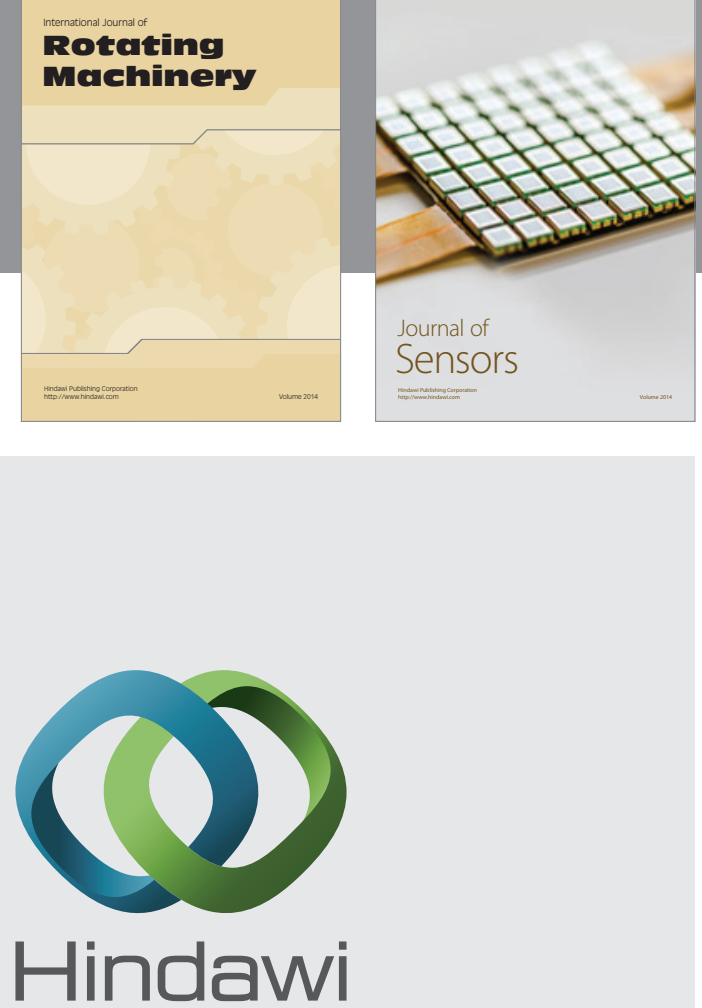

Submit your manuscripts at http://www.hindawi.com
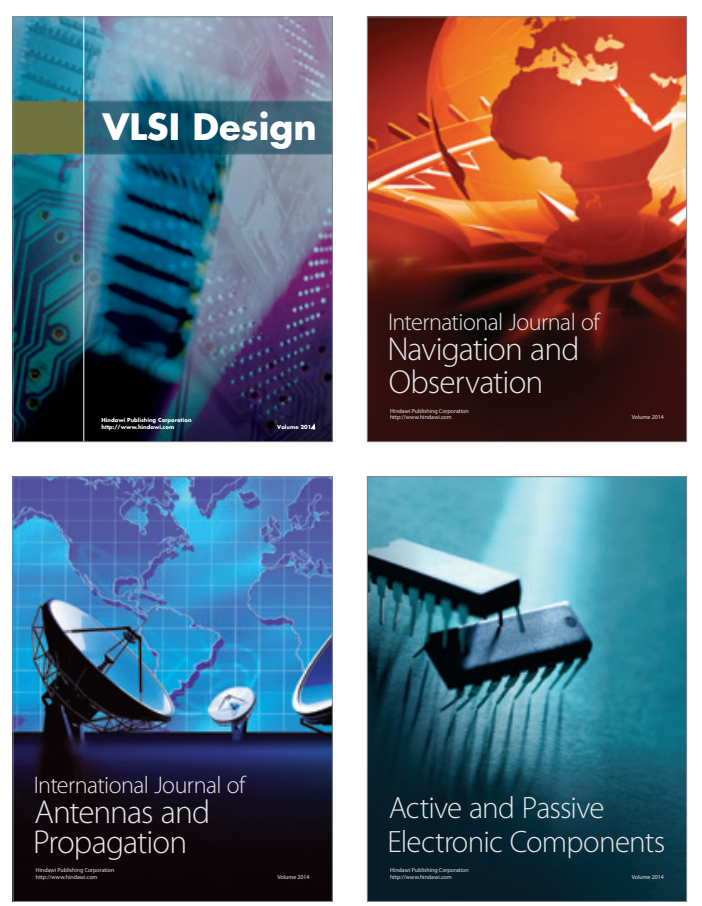
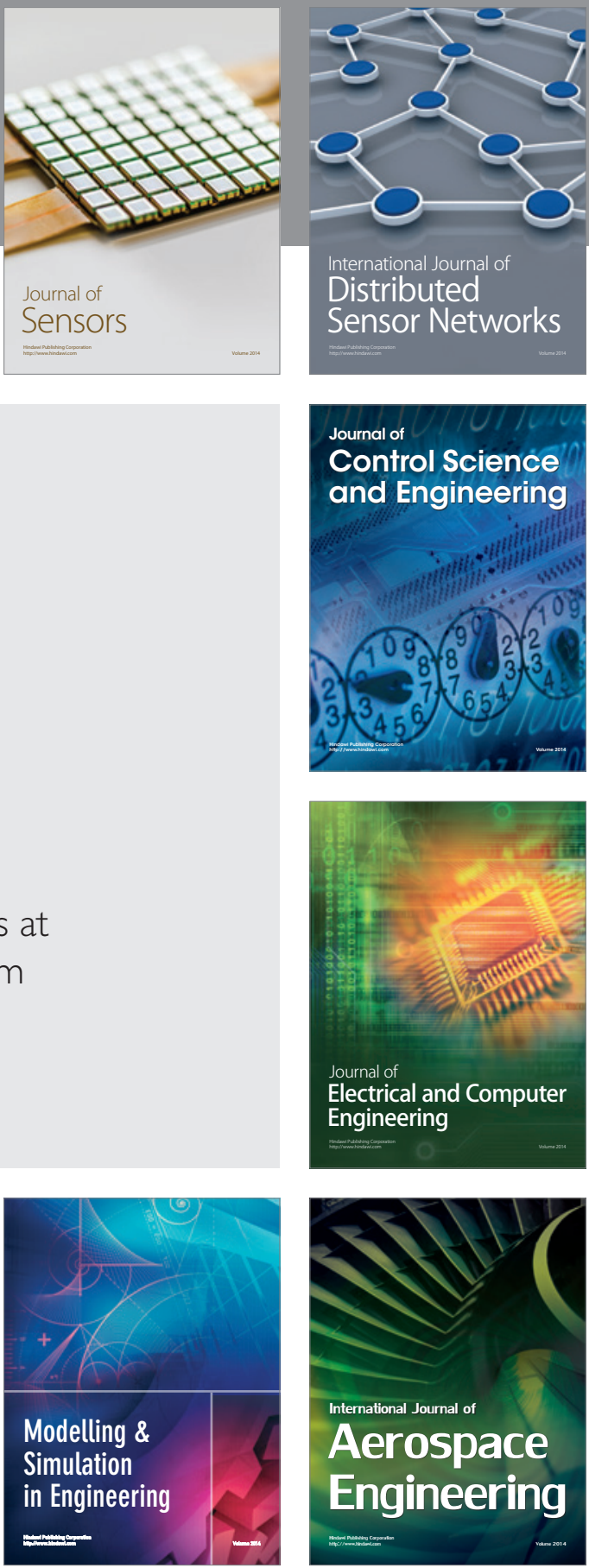

Journal of

Control Science

and Engineering
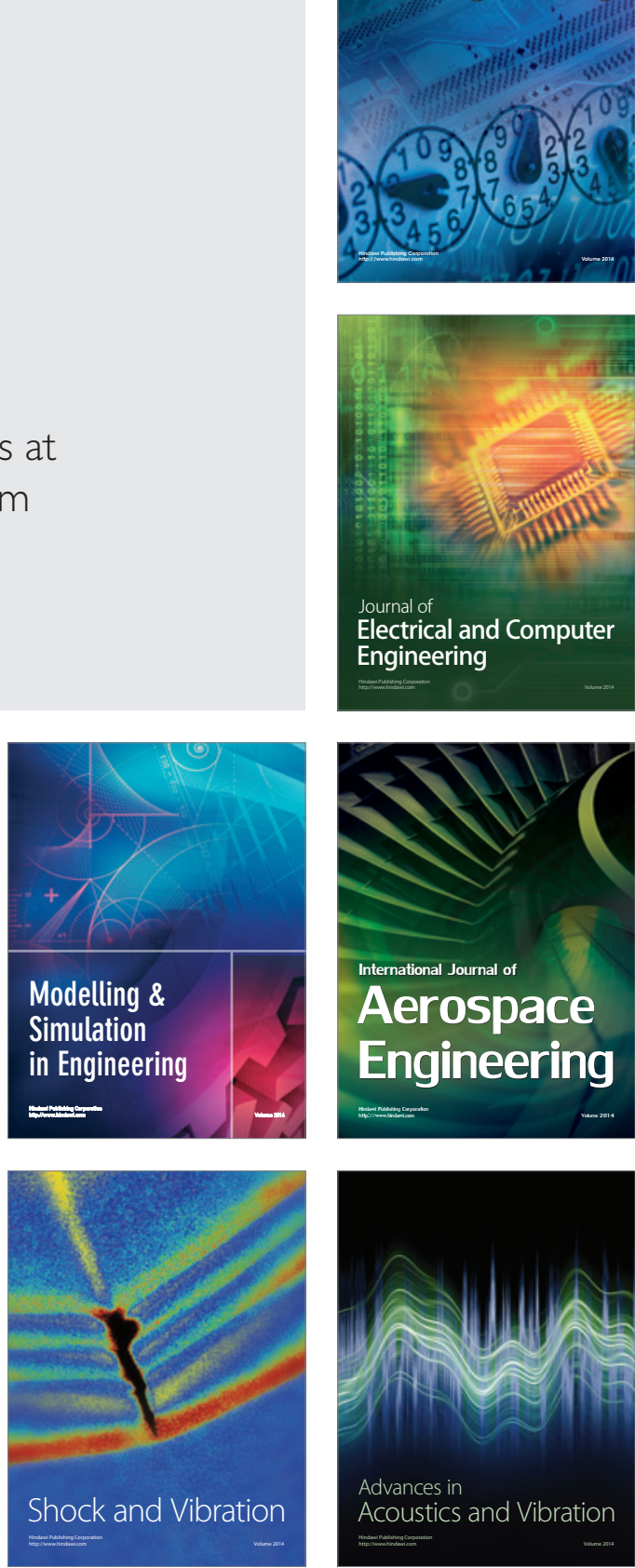